International Journal of Current Advanced Research

ISSN: O: 2319-6475, ISSN: P: 2319 - 6505, Impact Factor: SJIF: 5.995

Available Online at www.journalijcar.org

Volume 6; Issue 3; March 2017; Page No. 2639-2642

DOI: http://dx.doi.org/10.24327/ijcar.2017.2642.0063

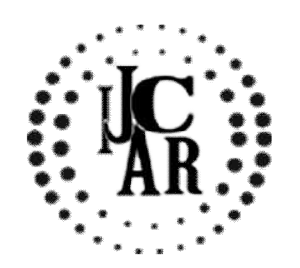

Research Article

\title{
CAN SONOGRAPHY ACT AS AN ADJUNCT IN ASSESSING AND ANTICIPATING THE SEVERITY OF DENGUE FEVER-OUR EXPERIENCE IN A TERTIARY HOSPITAL
}

\author{
*Vijaya Kamble \\ Department of Radiodiagnosis in NKPSIMS and Research Centre, Nagpur, \\ State-Maharashtra. Country India
}

\begin{tabular}{l}
\hline A R T I C L E I N F O \\
\hline Article History: \\
Received $19^{\text {th }}$ December, 2016 \\
Received in revised form $16^{\text {th }}$ January, 2017 \\
Accepted $26^{\text {th }}$ February, 2017 \\
Published online $28^{\text {th }}$ March, 2017
\end{tabular}

Key words:

Dengue fever, gall bladder wall thickening, pleural effusion, ascitis, platelet count, sonography ultrasound features.

\begin{abstract}
A B S T R A C T
Objective: The purpose of this study was to ascertain the use of ultrasound in speculating the severity of disease by correlating ultrasound imaging features with platelet count. If ultrasound serves as an important supplementary to the clinical and laboratory profile in diagnosing dengue fever was also studied. Materials and methods: 102 patients were studied retrospectively who were serologically positive for dengue fever between early September 2015 and 2016 to late october 2015 and 2016.These patients were sent for ultrasound examination of the abdomen and thorax and than imaging features were studied. Results: Of the 102 seropositive dengue patients, 65(63.72\%) showed GB Wall thickening, $35(34.31 \%)$ showed ascitis, $70(68.6 \%)$ showed bilateral pleural effusion,40 (39.21\%) showed hepatomegaly, 56 (54.91\%)showed splenomegaly and in $11(10.78 \%)$ patients USG study was found to be normal. In this study, one patient showed honey comb appearance of GB wall with GB wall measuring $10 \mathrm{~mm}$. Patients with platelet count of less than $40,000,100 \%$ showed GB wall thickening and pleural effusion and $50 \%$ showed ascitis. In patients with platelet count between $40,000-80,000$, pleural effusion was more common than GB wall thickening. Whearas patients with platelet count of $>1.5$ lac, still 11 patients were found to have persistent GB wall thickening. Conclusion: Sonographic imaging features of GB wall thickening, pleural effusion, ascitis, hepatomegaly, splenomegaly favoured the diagnosis of dengue fever especially during an epidemic in the postmonsoon period and the patient presenting clinically with fever and accompyning symptoms. Reduced platelet count showed a direct relationship to abnormal ultrasound features.
\end{abstract}

Copyright $\mathbb{C} 2017$ Vijaya Kamble. This is an open access article distributed under the Creative Commons Attribution License, which permits unrestricted use, distribution, and reproduction in any medium, provided the original work is properly cited.

\section{INTRODUCTION}

Dengue is a viral infection and is transmitted by mosquito aedes aegypti. In recent years, it has become a significant international health problem. It is commonly seen in tropical regions of South East Asia. Dengue clinically manifest with acute onset of fever, severe headache, joint pain, generalised bodyache and retroocular pain. Thrombocytopenia with hemorrhagic diasthesis is also manifested in these patients.

Serological tests are available to diagnose dengue but it takes approximately seven to ten days to give positive results.

Ultrasound imaging studies are carried out in serologically positive patients in different regions of the country. Many studies are already done concerning this issue, we carried out this study to analyse the ultrasound imaging features retrospectively, if these ultrasound imaging features acts as an adjunct to the clinical and laboratory findings in the diagnosis

*Corresponding author: Vijaya Kamble

Department of Radiodiagnosis in NKPSIMS and Research Centre, Nagpur, State-Maharashtra. Country India of dengue fever (DF), to evaluate if ultrasound is useful in anticipating the severity of the disease and to study the local scenario of this disease.

\section{MATERIALS AND METHODS}

This is a retrospective study carried out in tertiary care hospital of central India.102 patients serologically positive for dengue, admitted in the hospital from September 2015 and September 2016 to December 2015 and December 2016,were studied and analysed. The research protocol of this study was approved by the institutional ethical committee.

Inclusion criteria: of the 125 patients with clinical picture of suspected dengue like illness who underwent ultrasound examination, 23 patients turned out to be serologically negative. These 23 patients were excluded from the study. Only 102 patients who were found serologically positive were included in the study.

A real time gray scale ultrasound examination was done by using My lab 50 esaote machine, fitted with a 3.5 to $5 \mathrm{Mhz}$ 
curvilinear transducer with electronic callipers to measure GB wall thickness, hepatomegaly, splenomegaly.

Edematous GB wall thickening was measured by placing the electronic callipers between the two layers of the anterior wall of GB. For the assessment of pleural effusion, patient was assessed in sitting or supine position on both right and left side via intercostals approach. Hepatomegaly and splenomegaly was considered when liver and spleen measured more than $15 \mathrm{~cm}$ and more than $12 \mathrm{~cm}$ respectively.

To confirm the diagnosis of dengue fever, serological tests i.e NS-1 Ag test (non structural protein 1), dengue immunoglobulin $G$, dengue immunoglobulin $M$ test were performed. NS 1 is a glycoprotein present in high concentration in the serum of dengue patients. Corelation of platelet counts with ultrasound imaging features were also done. Reduced platelet counts of 40,000 , platelet count of 40,000 to 80,000 followed by platelet count of 80,000 to 1.5 lac and platelet count of more than 1.5 lac were the four groups of platelet counts into which the ultrasound imaging features are studied.

Sonography assessment was done by radiologist having a minimum of five years experience in abdominal sonography. Examination was done only once i.e when the patient was referred for sonography examination. So this rules out the interobserver variation.

Statistical analysis of data: Ultrasound features are the qualitative variables and they are expressed in percentage. These sonographic variables association with platelet count and age groups was assessed through chi square test of statistical significance. $\mathrm{P}$ value $\leq 0.05$ was considered to be statistically significant.

Total 102 serologically positive patient were further divided into four different age groups to study the distribution of ultrasound imaging features in these age groups.

Group 1comprised of patients from 0 to nine years(16 patients), group 2 had patients from more than 9 years to 19 years (18 patients), group 3 had patients from more than 19 years of age to 39 years (46 patients) and group 4 had patients of more than 39 years of age(22 patients).

\section{RESULTS}

Of the total 102 patients, 65 patients $(63.72 \%)$ had GB wall thickening, 35 (34.31\%) had ascitis, 70(68.6\%) had pleural effusion, 40 (39.21\%) had hepatomegaly, 56 (54.90\%) had splenomegaly and $11(10.78 \%)$ had normal sonography study.

Table 1 Incidence of various sonographic features in dengue fever

\begin{tabular}{cc}
\hline Total & 102 patients (100\%) \\
\hline USG features & Number (\%) \\
GB wall thickening & $65(63.72 \%)$ \\
Pleural effusion & $70(68.6 \%)$ \\
Right pleural effusion & $70(68.63 \%)$ \\
Left pleural effusion & $42(41.18 \%)$ \\
Ascitis & $35(34.31 \%)$ \\
Hepatomegaly & $40(39.21 \%)$ \\
Splenomegaly & $56(54.90 \%)$ \\
Normal sonography study & $11(10.78 \%)$ \\
USG-Ultrasonography & \\
\hline
\end{tabular}

Dengue was found to be more common in the age group of more than 19 years to 39 years i.e 46 patients $(45.09 \%)$. This was followed by group 4 i.e more than 39 years of age group which had 22 patients $(21.6 \%)$ GB wall thickening and pleural effusion was more common in group $4(81.8 \%)$ and group $3(63 \%)$. Hepatomegaly (13 patients, $81.2 \%)$ and pleural effusion (11 patients, $68.8 \%$ ) was commonly seen in 0-9 years age group.

Pleural effusion (90.9\%) was more common followed by edematous GB wall thickening $(81.8 \%)$ in group 4 patients i.e more than 39 years of age group and group $3(>19$ to 39 years). Also pleural effusion (p-0.000), hepatomegaly (p-0.003) and normal usg study reveal statistical significant (Table and graph) Combination of ultrasound imaging features among the different age groups were as described below. GB wall thickening, pleural effusion, ascitis were commonly associated with dengue fever in all age groups except $>9$ to 19 years.

In $>9$ to 19 years, it was found that GB wall thickening and hepatomegaly were commonly associated. Hepatomegaly was commonly seen in the age group of $>9$ to 19 years. Splenomegaly was commonly seen in age group of $>9$ to 39 years. Normal USG was common in $>9$ to 19 years of age group (5 patients, 27.8\%).

Correlation of platelet count and sonographic features .GB wall thickening was the commonest finding seen in all patients $(100 \%$ with $<40,000$ platelet count and frequently seen in platelet count of 40,000 to 80,000 i.e $(71.1 \%)$ and in $78.6 \%$ of patients with platelet count of $>1.5$ lac.

Pleural effusion and ascitis were the next common finding seen in patients with $<40,000$ platelet count and 40,000 to 80,000 platelet count.

In patients with platelet counts of 40,000-80,000, pleural effusion $(80 \%)$ was commonly seen than GB wall thickening $(71.1 \%)$. Splenomegaly was commonly seen in patients with platelet count of $>1.5$ lac $(78.6 \%$ followed by 40,000 to $80,000(53.3 \%)$.

Similarly hepatomegaly was commonly seen in patients with platelet count of $>1.5$ lac $(42.9 \%$ followed by 40,000 to $80,000(42.2 \%)$.

No abnormal sonography finding was seen in 10 patients with platelet count of $>80,000-1.5$ lac.

Reduced platelet count was associated with GB wall thickening $(p<0.001)$ and pleural effusion $(p<0.001$. This correlation was found to be statistically significant.

Tables 1 to 4;

\section{DISCUSSION}

Dengue fever patients were typically found in the post monsoon period.

Ultrasound imaging features of GB wall thickening, pleural effusion, ascitis, hepatomegaly in a patient presenting with fever especially in post monsoon period can most likely suggest the diagnosis of dengue fever. In Joshi et al ${ }^{1}$ study and Santosh et $a l^{2}$ study, common age group affected was 20 to 40 years. In our study also the common age group affected was 20-40 years. 
Table 2 Sonographic features and their relation with different age groups

\begin{tabular}{|c|c|c|c|c|c|c|}
\hline \multirow{3}{*}{ USG features } & \multicolumn{4}{|c|}{ Number of patients (\% of total) } & \multirow{3}{*}{$P$ value } & \multirow{3}{*}{$\begin{array}{c}\text { Statistical } \\
\text { significance }\end{array}$} \\
\hline & Group 1 & Group 2 & Group 3 & Group 4 & & \\
\hline & (0-9 years) & $>9$ to19years & $>19$ to 39years & $>39$ years & & \\
\hline Total & $16(15.7 \%)$ & $18(17.6 \%)$ & $46(45.09 \%)$ & $22(21.6 \%)$ & & \\
\hline GB Wall thickening & $9(56.2 \%)$ & $9(50 \%)$ & $29(63 \%)$ & $18(81.8 \%)$ & 0.17 & Not significant \\
\hline Pleural effusion & $11(68.8 \%)$ & $5(27.8 \%)$ & $34(73.9 \%)$ & $20(90.9 \%)$ & 0.00 & Significant \\
\hline Ascitis & $9(56.2 \%)$ & $3(16.7 \%)$ & $18(39.1 \%)$ & $5(22.7 \%)$ & 0.053 & Not significant \\
\hline Hepatomegaly & $13(81.2 \%)$ & $12(66.7 \%)$ & $22(47.8 \%)$ & $13(59.09 \%)$ & 0.003 & Significant \\
\hline Spleenomegaly & $9(5.2 \%)$ & $6(33.3 \%)$ & $29(63.0 \%)$ & $12(54.5 \%)$ & 0.201 & Not significant \\
\hline Normal USG & $2(12.5 \%)$ & $5(27.8 \%)$ & $4(8.7 \%)$ & $0(0.0 \%)$ & 0.040 & Significant \\
\hline
\end{tabular}

Table 3 Different combinations in different age groups

\begin{tabular}{ccccc}
\hline & \multicolumn{4}{c}{ Age groups } \\
\cline { 2 - 5 } USG features & $\begin{array}{c}\text { Group 1 } \\
\text { 0-9 years }\end{array}$ & $\begin{array}{c}\text { Group 2 } \\
>\text { 9 to 19 } \\
\text { years }\end{array}$ & $\begin{array}{c}\text { Group 3 } \\
>\text { 19 to 39 } \\
\text { years }\end{array}$ & $\begin{array}{c}\text { Group 4 } \\
\text { >39 years }\end{array}$ \\
\hline Total & 16 & 18 & 46 & 22 \\
GBWT+ASC & 5 & 3 & 12 & 5 \\
GBWT+ASC+PE & 5 & 3 & 11 & 5 \\
GBWT+ASC+PE+SPM & 3 & 2 & 8 & 4 \\
GBWT+ASC+PE+SPM+HPM & 3 & 1 & 6 & 4 \\
GBWT+ASC+PE+HPM & 3 & 2 & 7 & 5 \\
SPM+HPM & 3 & 1 & 21 & 12 \\
ASC+PE & 5 & 3 & 17 & 5 \\
ASC+SPM & 5 & 2 & 14 & 17 \\
GBWT+PE & 9 & 3 & 24 & 13 \\
GBT+HPM & 3 & 2 & 18 & 5 \\
ASC+HPM & 3 & 2 & 11 & \\
\hline
\end{tabular}

Table 4 Corelation of platelet count and sonographic features

\begin{tabular}{|c|c|c|c|c|c|c|}
\hline \multirow{2}{*}{ USG features } & \multicolumn{4}{|c|}{ Number (\%) } & \multirow{2}{*}{$\begin{array}{l}\text { p value } \\
\leq 0.05\end{array}$} & \multirow[t]{2}{*}{$\begin{array}{c}\text { Statistical } \\
\text { significance }\end{array}$} \\
\hline & $<40,000$ & $40,000-80,000$ & $>80,000-150,000$ & $>150,000$ & & \\
\hline Total & $6(5.9 \%)$ & $45(44.1 \%)$ & $37(36.3 \%)$ & $14(13.7 \%)$ & & \\
\hline GB Wall thickening & $6(100 \%)$ & $32(71.1 \%)$ & $16(43.2 \%)$ & $11(78.6 \%)$ & 0.006 & Significance \\
\hline Pleural effusion & $6(100 \%)$ & $36(80 \%)$ & $21(56.8 \%)$ & $7(50 \%)$ & 0.018 & Significant \\
\hline Ascitis & $3(50 \%)$ & $17(37.8 \%)$ & $13(35.1 \%)$ & $2(14.3 \%)$ & 0.334 & Not significant \\
\hline Hepatomegaly & $2(33.3 \%)$ & $19(42.2 \%)$ & $13(35.1 \%)$ & $6(42.9 \%)$ & 0.898 & Not significant \\
\hline Spleenomegaly & $2(33.3 \%)$ & $24(53.3 \%)$ & $19(51.4 \%)$ & $11(78.6 \%)$ & 0.210 & Not significant \\
\hline Normal USG & $0(0 \%)$ & $0(0 \%)$ & $10(27 \%)$ & $1(7.1 \%)$ & - & - \\
\hline
\end{tabular}

In Joshi et $a l^{1}$ study, it was the right pleural effusion (66\%) followed by ascitis $(50 \%)$ the common ultrasound imaging finding.

In Santosh et $a l^{2}$ study, it was GB wall thickening $(66.7 \%)$ followed by ascitis (64.5\%) and than right pleural effusion $(60 \%)$, the common ultrasound imaging feature.

In a study by Bhangdiya et $a l^{3}$, GB wall thickening $(100 \%)$ followed by right pleural effusion (97.72\%) were the commonest ultrasound imaging features. Ascitis was found in $86.36 \%$.

Similarly Venkatasai et $a l^{4}$ also found GB wall thickening $(100 \%)$ and right pleural effusion $(96.46 \%)$ to be the commonest USG imaging features.

In our study, the commonest ultrasound finding was right pleural effusion $(68.6 \%)$. This is consistent with Joshi et al ${ }^{1}$. But in the present study, this was followed by GB wall thickening (63.72\%) and ascitis (34.31\%).

In 1991, Pramuljo and Harun ${ }^{5}$ reported GB wall thickening in $18 \%$ children with dengue fever.

In a study by Chacko and Subramanian ${ }^{6}$, presence of ascitis and pleural effusion were found to be most predictive indicators of dengue fever and not GB Wall thickening, in children.
Whereas in our study, it was hepatomegaly $(81.2 \%)$, pleural effusion $(68.8 \%)$ commonly found in children of group I (0-9 years).

In a study by Venkatasai ${ }^{4}$ et al, in children hepatomegaly was commonly seen in dengue fever as a result of volumetric increase of organs, whearas splenomegaly and pancreatomegaly was less commonly seen in dengue fever ${ }^{7,8,9}$. In the present study also hepatomegaly was commonly seen as compared to other organomegaly.

In the present study, pleural effusion was either bilateral or right sided but never left sided alone. Same was observed in Sachar et $a l^{10}$ study.

In Sachar et $a l^{10}$ study, honey comb pattern thickening of the GB wall especially in the fundal region was described as the diagnostic sign and prognostic sign as well in Dengue hemorrhagic fever.

In the present study, only one case of GB wall thickening with honey comb appearance is noted, in a child of seven years old clinically presented with fever and subsequently found to be serologically positive for dengue.

Pericardial effusion was found in $28.12 \%$ patients of dengue in a Venkatasai et $a l^{4}$ study. In present study 10 patients $(9.8 \%)$ showed pericardial effusion. 
These different observations could be related to the changing scenario of dengue fever.

Different combinations of sonographic findings in different age groups were also studied. In group I, III and IV, it was the GB wall thickening and pleural effusion, the commonest combination found. In group II, varied combinations were found. In Santosh et $a l^{2}$ study, the commonest combination found was GB wall thickening+ ascitis + pleural effusion in all the age groups.

As it was observed in previous studies i.e Santosh et $a l^{2}$, the platelet count and the severity of course of disease were closely related. In our study also, it was found that GB wall thickening and pleural effusion was found in $100 \%$ of patients with platelet count of $<40,000$. In patients with platlet count of 40,000 to 80,000, pleural effusion (80\%) and GB wall thickening (71.1\%) was the common finding. This correlation of platelet count and GB wall thickening, pleural effusion was found to be statistically significant.

Hepatomegaly was found in $81.2 \%$ of group 1 patients, $66.7 \%$ of group 2, $47.8 \%$ of group 3 and $59.09 \%$ of group 4 . This was found to be statistically significant.

Also pleural effusion was found in $68.8 \%$ of group 1 patients, $27.8 \%$ in group 2 patients, $73.9 \%$ in group 3 patients and $90.9 \%$ of group 4 . This relation was found to be statistically significant.

\section{CONCLUSION}

Dengue fever is most commonly found in young adults, typically in the post monsoon period. Ultrasound examination definitely acts as an adjunct to the diagnosis of dengue fever if patient presents with fever in the post monsoon period with no available positive serology. Ultrasound imaging findings of right pleural effusion or bilateral pleural effusion, GB wall thickening, ascitis should favour the diagnosis of dengue fever. Ultrasound imaging features also helps in anticipating the severity of disease. It is also concluded that there is changing scenario of dengue fever from region to region, regarding the ultrasound imaging features.

\section{References}

1. Joshi P, Rathnam VG, Sharma S.USG findings in dengue haemorrhagic fever-our experience in the recent epidemic. Ind J Radiol Imag 1997;7:189-92

2. Santosh VR, Patil PG, Srinath MG, Kumar A, Jain A, Archana M. Sonography in the diagnosis and assessment of Dengue Fever. J Clin Imaging Sci 2014; $4: 14$

3. Omprakash Bhangdia, Suresh Bhattad, Kirti Bhangdiya. Ultrasound findings in dengue fever. Journal of Recent Trends in Science and Technology. April 2016; 18(3)486-488.

4. Venkata Sai PM, Dev B, Krishnan R. Role of ultrasound in dengue fever. The British Journal of Radiology 2005; 78:416-418.

5. Pramuljo HS, Harun SR. Ultrasound findings in dengue hemorrhagic fever. Pediatr Radiol.1991;21:100-2

6. Chacko B, Subramanian G. Clinical, laboratory and radiological parameters in children with dengue fever and predictive factors for dengue shock syndrome. J Trop Pediatr.2008; 54:137-40.

7. Oliveira RVB, Rios LTM, Branco MRFC, Braga Junior LL, Nascimento JMS, Silva GF, Bandeira KP. Usefulness of ultrasonography in children with suspected dengue hemorrhagic fever: a literature review. Radiol Bras.2010; 43(6):401-407.

8. Setiawan MW, Samsi TK, Wulur H, et al. Dengue haemorrhagic fever: ultrasound as an aid to predict the severity of the disease. Pediatr Radiol. 1998; 28:1-4.

9. Balasubramanian S, Janakiraman L, Kumar SS et al. A reappraisal of the criteria to diagnose plasma leakage in dengue hemorrhagic fever. Indian Pediatr. 2006; 43:334-9.

10. Sudhir Sachar, Sunder Goyal, Saurabh Sachar .Role of Ultrasonography ("Honeycomb Sign") in Early Detection of Dengue Hemorrhagic Fever. Archives of Clinical Experimental Surgery. 2013; 2(1):38-42

Please cite this article in press as:

Vijaya Kamble (2017), Can sonography act as an adjunct in assessing and anticipating the Severity of dengue fever-our experience in a tertiary hospital, International Journal of Current Advanced Research, 6(3), pp. 2639-2642.

http://dx.doi.org/10.24327/ijcar.2017. 2642.0063 